\title{
High-Speed Study of Drop-Weight Impact Ignition of PBX 9501 Using Infrared Thermography
}

\author{
Emily M. Hunt, ${ }^{1}$ Steve Malcolm, ${ }^{2}$ and Matt Jackson ${ }^{1}$ \\ ${ }^{1}$ Mechanical Engineering, West Texas A\&M University, Canyon, TX 79016, USA \\ ${ }^{2}$ Applied Technology Division, B\&W Pantex Plant, Amarillo, TX 79119, USA
}

Correspondence should be addressed to Emily M. Hunt, ehunt@wtamu.edu

Received 11 January 2011; Accepted 10 February 2011

Academic Editor: A. Tounsi

Copyright (C 2011 Emily M. Hunt et al. This is an open access article distributed under the Creative Commons Attribution License, which permits unrestricted use, distribution, and reproduction in any medium, provided the original work is properly cited.

\begin{abstract}
Reaction in explosive materials does not occur as a result of homogenous heating of the sample, but rather from a localized region of high temperature called a hot spot. Observation of hot spot development is critical in understanding the heat transfer mechanisms occurring during reaction. Due to the strong temperature dependence of explosives, the overall reaction rate is dominated physically by these hot spots. Once formed, these hot spots either fail to react chemically due to thermal diffusion or react exothermically thus creating an ignition site in the solid explosive. The slightest difference of physical properties can change the positioning of hot spot development, creating an argument that the differences in material properties influence the formation of hot spots, which produce an exothermic reaction.
\end{abstract}

Reaction in explosive materials does not occur as a result of homogenous heating of the sample, but rather from a localized region of high temperature called a hot spot [1-7]. Observation of hot spot development is critical in understanding the heat transfer mechanisms occurring during reaction. Due to the strong temperature dependence of explosives, the overall reaction rate is dominated physically by these hot spots [8-10]. Once formed, these hot spots either fail to react chemically due to thermal diffusion or react exothermically thus creating an ignition site in the solid explosive. The slightest difference of physical properties can change the positioning of hot spot development, creating an argument that the differences in material properties influence the formation of hot spots, which produce an exothermic reaction [10].

Bowden et al. [2-7] suggests that the critical size for ignition of a hot spot is around $10 \mu \mathrm{m}$ in diameter with temperatures in excess of $500^{\circ} \mathrm{C}$. PBX 9501 has a bimodal crystal size distribution centered at 25 and $130 \mu \mathrm{m}$ [4]. Bowden and Gurton [3] also showed through earlier experiments that the kinetic energy available in a drop-weight impact tester is only capable of raising the temperature of the material by a few degrees. So, it is apparent that some other form of localized energy development is necessary to lead to hot spot formation and ignition. Bouma et al. [11] explains that particle size distribution is an important property in influencing both sensitivity to mechanical deformation and reactivity of the material.

The impact sensitivity PBX 9501 was investigated using a modified type 12 impact tester (Figure 1, Key Kinetics, Inc.) in conjunction with a FLIR SC6000 thermal imaging camera and R-tools data acquisition software. High-speed infrared imaging is a novel method for studying the impact ignition of explosives. The impact tester has a drop mass of $1 \mathrm{~kg}$ with an intermediate mass of $1.5 \mathrm{~kg}$. Each test was conducted with 30 $\pm 5 \mathrm{mg}$ pressed sample placed on the anvil. The intermediate mass is rested on the specimen, and the drop mass makes contact with the top of the intermediate mass (Figure 1).

The drop mass is released from a variable height, and the infrared camera is used to determine ignition based on a go/no-go determination. Once an optimal range is found in which there are positive and negative reactions, tests are conducted on $1 \mathrm{~cm}$ intervals. Using an abbreviated Bruceton method, the lowest drop height that produces a greater than 


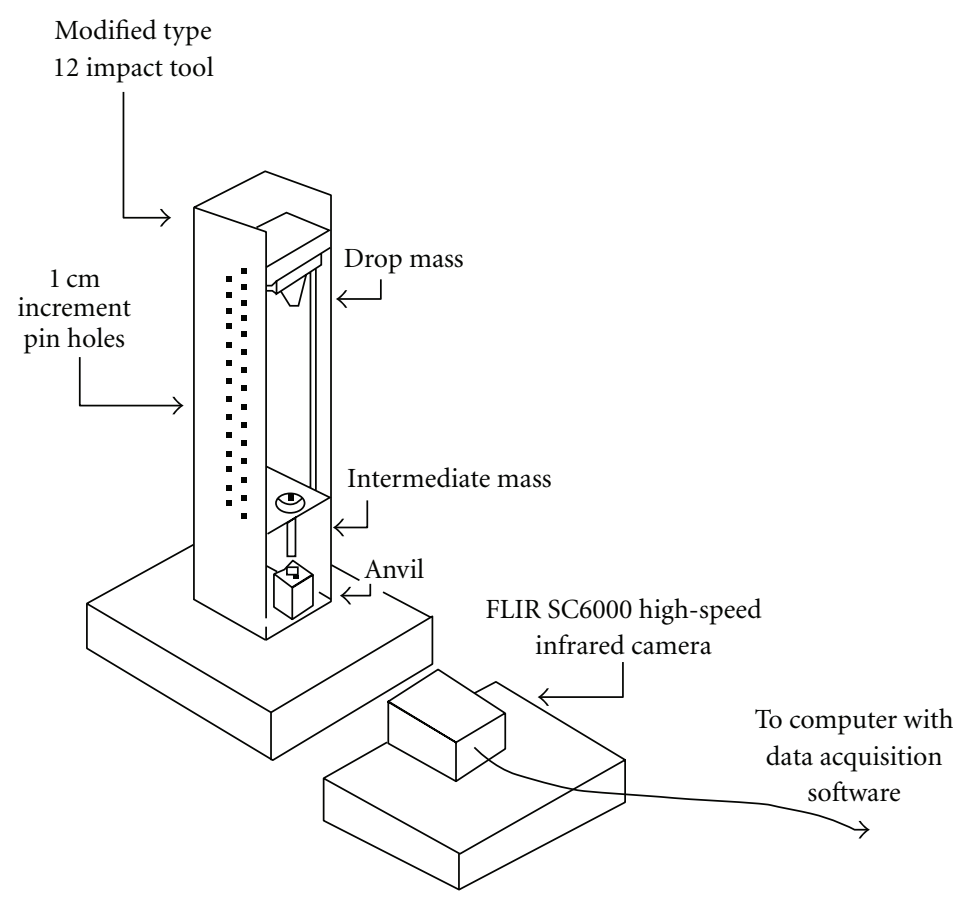

FIGURE 1: Experimental setup.

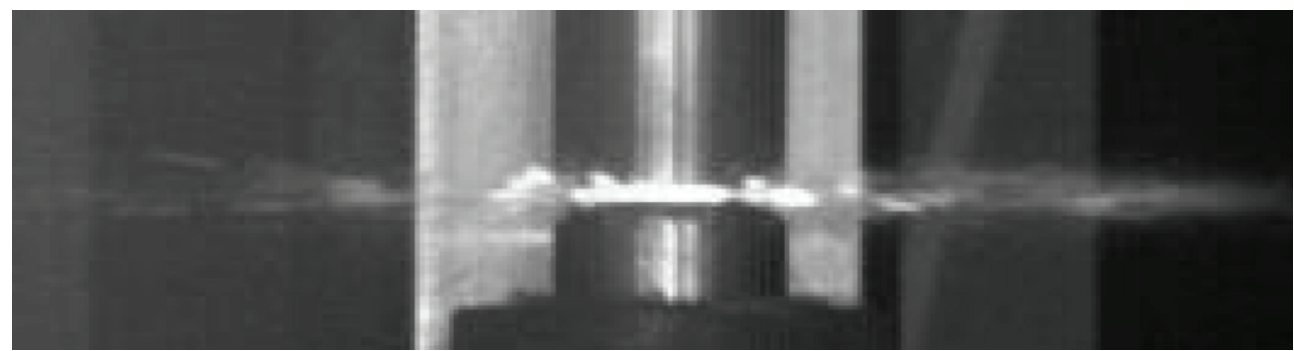

FIGURE 2: High-speed infrared image of impact.

$50 \%$ reaction is used to calculate ignition energy through potential energy. The infrared camera is used to determine the velocity of the drop mass as it travels to the sample. The high-speed capabilities of the SC6000 (4000 fps) are also an effective tool to measure the time between initial contact and ignition of the sample.

Impact sensitivity was also examined as a result of thermal insult or indirect heating. Two different sets of samples were tested: undamaged or pristine samples and damaged samples of PBX 9501. The material was damaged by indirect exposure in a volumetric combustion oven at $250^{\circ} \mathrm{C}$ for 1 hour. The exposure is considered indirect because the samples were enclosed in another container inside of the oven so that the material was not directly exposed to the heat source.

Frictional heating is identified and widely accepted as a cause of ignition in the drop-weight system due to the interaction and plastic deformation of the spherical particles [8-20]. Photographic data during the drop-weight impact testing shows the sample compresses and then fragments
[20] (Figure 2). Previous research [8-15, 21] shows that when this happens, small gas spaces become trapped and ignition occurs because of the collapse of this gas space. Adiabatic shear bands are clearly forming in and around the sintered region (Figures 3 and 4). The ignition site (Figure 4) develops in the vicinity of the shear bands and the reaction appears to spread radially along the shear bands. The reaction continues to propagate and consume the entire sample.

Table 1 shows the ignition energies measured with the drop weight apparatus at high fire, low fire, and Bruceton method. High-fire conditions require a $90 \%$ positive reaction while low-fire conditions require a $10 \%$ positive reaction. The Bruceton method was also used and is based on a $50 \%$ positive reaction.

It is important to note that all of the damaged samples of PBX 9501 reacted below the low fire conditions for undamaged PBX 9501. In other words, the damaged material reacts $100 \%$ of the time at the same height that undamaged material reacts $10 \%$ of the time. 


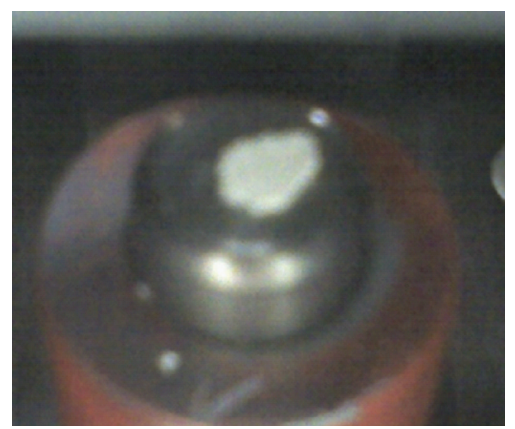

(a)

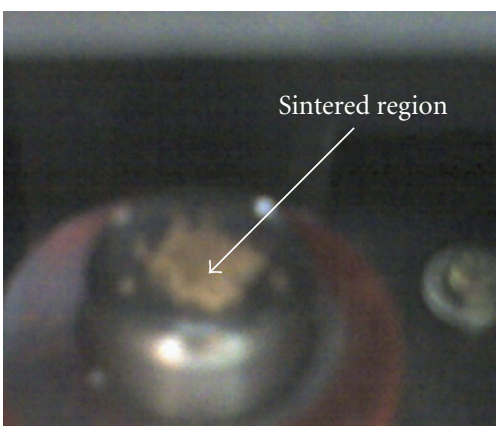

(b)

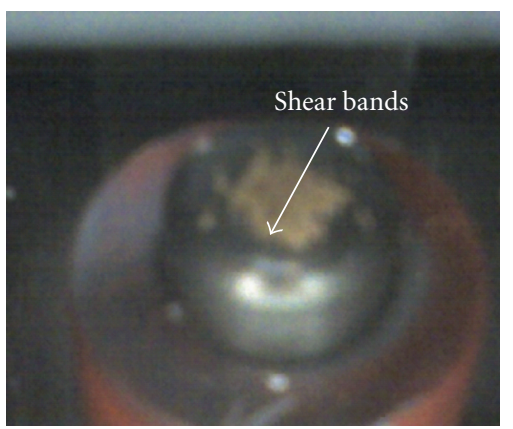

(c)

Figure 3: Photographic sequence of impact.

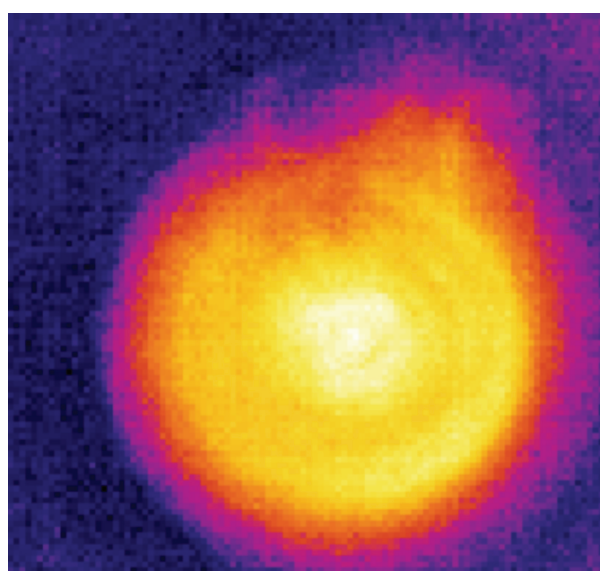

(a)

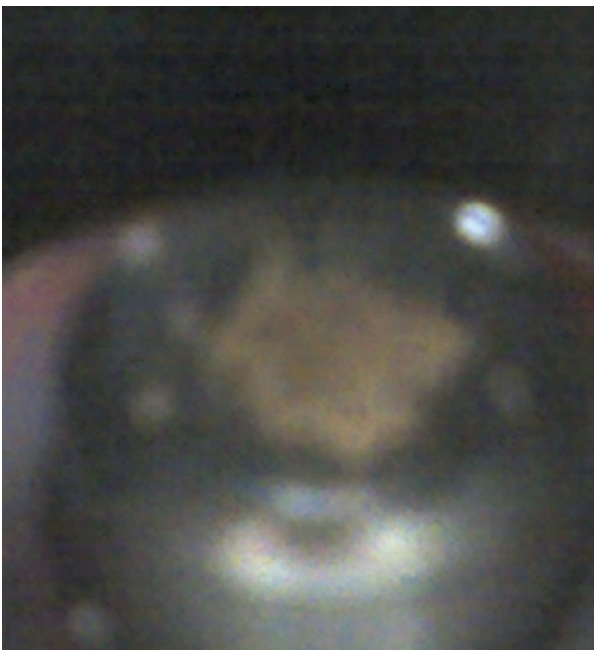

(b)

Figure 4: (a) Thermogram of PBX 9501 during impact (the white region is at $341^{\circ} \mathrm{C}$ and the dark outer regions are at $23^{\circ} \mathrm{C} \pm 0.8$ ), $(\mathrm{b})$ Simultaneous photographic image.

TABLE 1: Ignition energies from impact testing of undamaged PBX 9501.

\begin{tabular}{|c|c|c|c|c|c|c|}
\hline PBX 9501 & $\operatorname{High}(\mathrm{m})$ & Low $(\mathrm{m})$ & $50 \%(\mathrm{~m})$ & $\operatorname{High}(\mathrm{J})$ & Low $(\mathrm{J})$ & $50 \%(\mathrm{~J})$ \\
\hline Sample 1 & 0.20 & 0.13 & 0.13 & 1.96 & 1.28 & 1.28 \\
\hline Sample 2 & 0.13 & 0.06 & 0.09 & 1.28 & 0.59 & 0.88 \\
\hline Sample 3 & 0.12 & 0.10 & 0.11 & 1.18 & 0.98 & 1.08 \\
\hline Sample 4 & 0.10 & 0.07 & 0.08 & 0.98 & 0.69 & 0.78 \\
\hline Sample 5 & 0.10 & 0.06 & 0.08 & 0.98 & 0.59 & 0.78 \\
\hline Sample 6 & 0.09 & 0.07 & 0.08 & 0.88 & 0.69 & 0.78 \\
\hline Sample 7 & 0.13 & 0.07 & 0.08 & 1.28 & 0.69 & 0.78 \\
\hline Sample 8 & 0.13 & 0.10 & 0.12 & 1.28 & 0.98 & 1.18 \\
\hline Average & 0.13 & 0.08 & 0.10 & 1.23 & 0.81 & 0.94 \\
\hline St. Dev. & 0.034 & 0.025 & 0.021 & & & \\
\hline
\end{tabular}


Several hot spot mechanisms are operating during the drop-weight studies on PBX 9501. The frictional heating between the particles of explosive material and both the anvils and each other helped initially to raise the temperature of the sample. Thermograms of the reactions show adiabatic shear banding which creates localized energy of the system and creates hot spots as well as trapped gas that becomes compressed during impact. The size of the gas pocket is dependent on the grain size of the sample.

The results clearly show that PBX 9501 becomes more sensitive to mechanical impact after exposure to indirect heating. The results show that for indirect exposure at $250^{\circ} \mathrm{C}$ for 1 hour, the impact ignition threshold of PBX 9501 for highfire conditions drops at least $80 \%$. This is a very important safety consideration both for storage and machining of this explosive material.

\section{References}

[1] M. J. Gifford, W. G. Proud, and J. E. Field, "Development of a method for quantification of hot-spots," Thermochimica Acta, vol. 384, no. 1-2, pp. 285-290, 2002.

[2] F. P. Bowden, M. A. Stone, and G. K. Tudor, "Hot spots on rubbing surfaces and the detonation of explosives by friction," Proceedings of the Royal Society of London A, vol. 188, pp. 329349, 1947.

[3] F. P. Bowden and O. A. Gurton, "Birth and growth of the explosion in solids initiated by impact," Nature, vol. 161, no. 4088, p. 348, 1948.

[4] F. P. Bowden, "Hot spots and the initiation of explosion," Symposium on Combustion and Flame, and Explosion Phenomena, vol. 3, no. 1, pp. 551-560, 1949.

[5] F. P. Bowden and O. A. Gurton, "Birth and growth of explosion in liquids and solids initiated by impact and friction," Proceedings of the Royal Society London A, vol. 198, pp. 350-372, 1949.

[6] F. P. Bowden and O. A. Gurton, "Initiation of solid explosives by impact and friction: the influence of grit," Proceedings of the Royal Society London A, vol. 198, pp. 337-349, 1949.

[7] F. P. Bowden and A. D. Yoffe, Initiation and Growth of Explosion in Liquids and Solids, Cambridge University Press, Cambridge, UK, 1952.

[8] J. E. Field, G. M. Swallowe, and S. N. Heavens, "Ignition mechanisms of explosives during mechanical deformation," Proceedings of The Royal Society of London. Series A, vol. 382, no. 1782, pp. 231-244, 1982.

[9] J. E. Field, "Hot spot ignition mechanisms for explosives," Accounts of Chemical Research, vol. 25, no. 11, pp. 489-496, 1992.

[10] J. E. Field, N. K. Bourne, S. J. P. Palmer, and S. M. Walley, "Hotspot ignition mechanisms for explosives and propellants," Philosophical Transactions of the Royal Society London A, vol. 339, pp. 269-283, 1992.

[11] R. H. B. Bouma, D. Meuken, R. Verbeek, M. M. Pacheco, and L. Katgerman, "Shear initiation of Al/MoO-based reactive materials," Propellants, Explosives, Pyrotechnics, vol. 32, no. 6, pp. 447-453, 2007.

[12] S. M. Walley, J. E. Field, and S. J. P. Palmer, "Impact sensitivity of propellants," Proceedings of the Royal Society London A, vol. 438, pp. 571-583, 1992.
[13] S. M. Walley, J. E. Balzer, W. G. Proud, and J. E. Field, "Response of thermites to dynamic high pressure and shear," Proceedings of the Royal Society A, vol. 456, no. 1998, pp. 14831503, 2000.

[14] S. M. Walley, J. E. Field, and M. W. Greenaway, "Crystal sensitivities of energetic materials," Materials Science and Technology, vol. 22, no. 4, pp. 402-413, 2006.

[15] J. E. Balzer, J. E. Field, M. J. Gifford, W. G. Proud, and S. M. Walley, "High-speed photographic study of the drop-weight impact response of ultrafine and conventional PETN and RDX," Combustion and Flame, vol. 130, no. 4, pp. 298-306, 2002.

[16] H. L. Berghout, S. F. Son, C. B. Skidmore, D. J. Idar, and B. W. Asay, "Combustion of damaged PBX 9501 explosive," Thermochimica Acta, vol. 384, no. 1-2, pp. 261-277, 2002.

[17] J. E. Field, S. M. Walley, W. G. Proud, H. T. Goldrein, and C. R. Siviour, "Review of experimental techniques for high rate deformation and shock studies," International Journal of Impact Engineering, vol. 30, no. 7, pp. 725-775, 2004.

[18] F. P. Bowden, "The development of combustion and explosion in liquids and solids," Symposium (International) on Combustion, vol. 4, no. 1, pp. 161-172, 1953.

[19] B. F. Henson, B. W. Asay, R. K. Sander, S. F. Son, J. M. Robinson, and P. M. Dickson, "Dynamic measurement of the HMX $\beta-\delta$ phase transition by second harmonic generation," Physical Review Letters, vol. 82, no. 6, pp. 1213-1216, 1999.

[20] J. E. Balzer, W. G. Proud, S. M. Walley, and J. E. Field, "Highspeed photographic study of the drop-weight impact response of RDX/ DOS mixtures," Combustion and Flame, vol. 135, no. 4, pp. 547-555, 2003.

[21] V. K. Mohan and J. E. Field, "Impact initiation of hexanitrostilbene," Combustion and Flame, vol. 56, no. 3, pp. 269-277, 1984. 

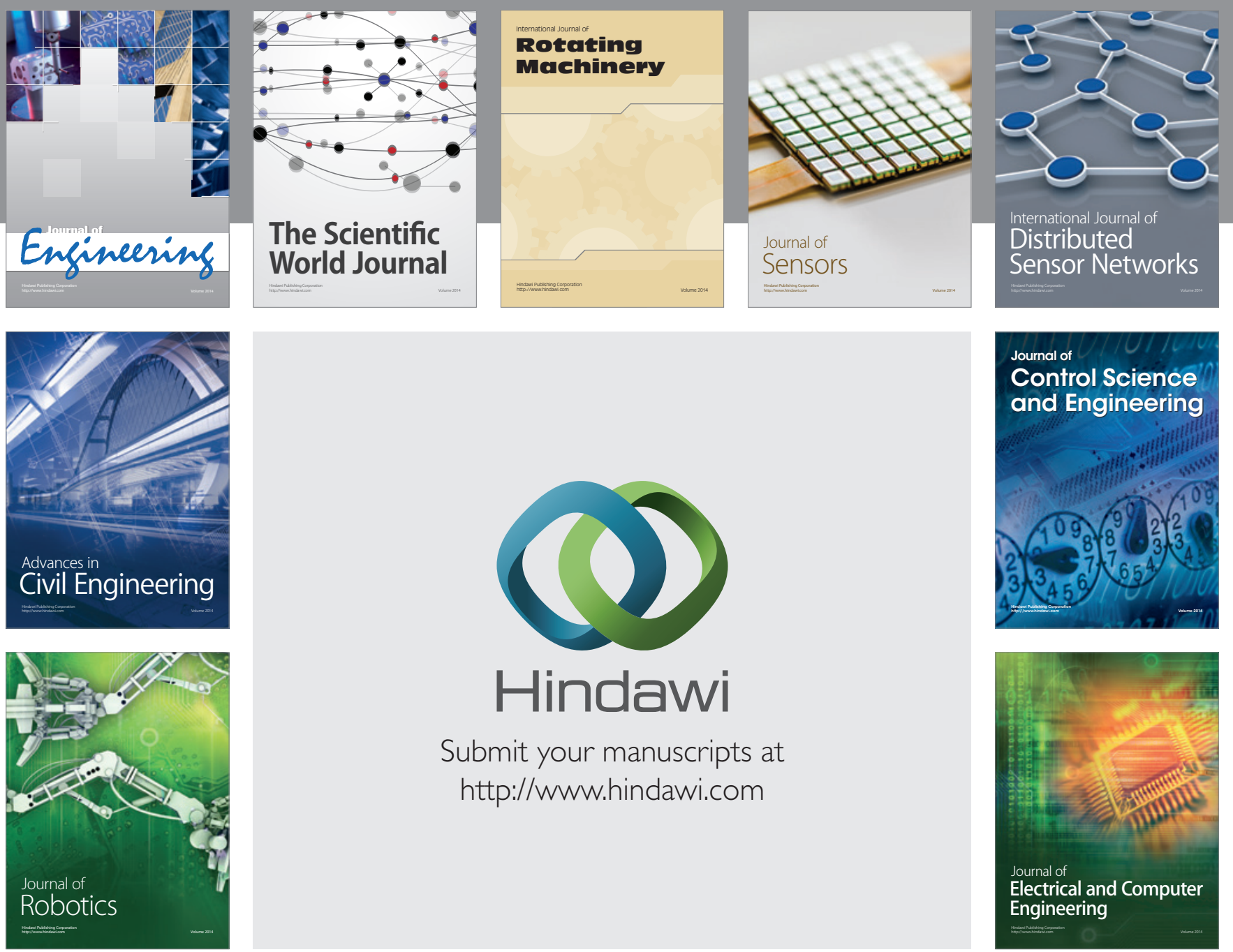

Submit your manuscripts at

http://www.hindawi.com
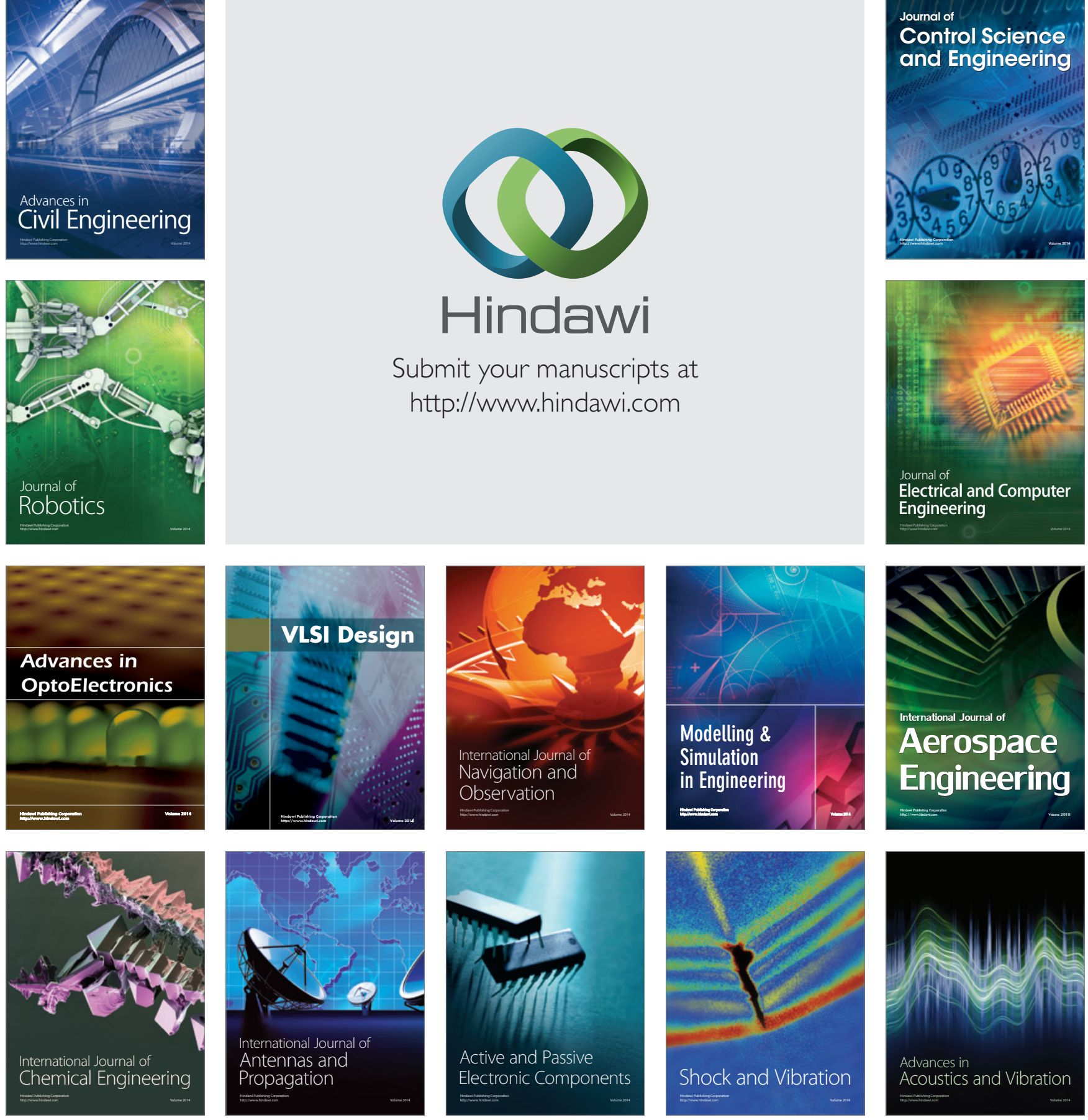